\title{
Comparison of TMA Technique and Routine Whole Slide Analysis in Evaluation of Proliferative Markers Expression in Laryngeal Squamous Cell Cancer
}

\author{
URSZULA CIESIELSKA ${ }^{1}$, ALEKSANDRA PIOTROWSKA ${ }^{1}$, CHRISTOPHER KOBIERZYCKI ${ }^{1}$, \\ WOJCIECH PASTUSZEWSKI ${ }^{2}$, MARZENNA PODHORSKA-OKOLOW ${ }^{3}$, \\ PIOTR DZIEGIEL ${ }^{1,4}$ and KATARZYNA NOWINSKA ${ }^{1}$ \\ ${ }^{1}$ Division of Histology and Embryology, Department of Human Morphology \\ and Embryology, Wroclaw Medical University, Wroclaw, Poland; \\ ${ }^{2}$ Department of Otolaryngology, Municipal Hospital, Namsos, Norway; \\ ${ }^{3}$ Division of Ultrastructure Research, Department of Human Morphology and Embryology, \\ Wroclaw Medical University, Wroclaw, Poland; \\ ${ }^{4}$ Department of Physiotherapy, Wroclaw University School of Physical Education, Wroclaw, Poland
}

\begin{abstract}
Background/Aim: Comparison of the expression of $\mathrm{Ki}-67, \mathrm{MCM} 3,5,7$ and MTI/II proteins using immunohistochemistry (IHC) on whole section (WS) and tissue microarray (TMA) of laryngeal squamous cell carcinoma (LSCC) samples. Materials and Methods: A total of 51 archival paraffin blocks of LSCC were used. TMAs were prepared from $1.5 \mathrm{~mm}$ core punches. IHC reactions were performed using antibodies against Ki-67, minichromosome maintenance proteins (MCM3, 5, 7) and metallothionein (MTI/II). Results: Spearman rank correlation test revealed moderate positive correlation in the case of Ki-67: WS vs. TMA ( $r=0.38, p=0.07)$ and strong positive correlation in regard to the rest of tested markers: MCM3, WS vs. TMA ( $r=0.49, p=0.0004)$; MCM5, WS vs. TMA ( $r=0.61, p<0.0001)$; MCM7, WS vs. TMA ( $r=0.59$, $p<0.0001)$; MTI/II, WS vs. TMA ( $r=0.66, p<0.0001)$. Mann Whitney $U$-test showed no significant differences in the case of Ki-67 and MCM5. Moreover, Bland-Altman test showed a low level of bias in regard to Ki-67, WS vs. TMA and MCM5, WS vs. TMA. Conclusion: TMA may be an effective and reliable method of assessment of Ki-67 and MCM5 expression in LSCC.
\end{abstract}

This article is freely accessible online.

Correspondence to: Urszula Ciesielska, Ph.D., Division of Histology and Embryology, Department of Human Morphology and Embryology, Wroclaw Medical University, Chalubinskiego 6a, 50368 Wroclaw, Poland. Tel: +48 717841368, Fax: +48 717840082, e-mail: urszula.ciesielska@umed.wroc.pl

Key Words: Tissue microarray, TMA, laryngeal cancer, Ki-67, MCM3, 5, 7, MTI/II.
Over the last two decades, the tissue microarray (TMA) technique has developed and became a commonly used research tool to estimate associations between biomarkers and clinicopathological factors associated with cancer development $(1,2)$. TMAs were first described by H. Battifora in 1986, and then in $1998 \mathrm{~J}$. Kononen and collaborators developed a device for fast and repeatable production of TMAs. Since then, this technique has been increasingly used in cancer research $(3,4)$. The technique utilizes small $(0.6$ to $2.0 \mathrm{~mm}$ in diameter) histological tissue samples in the form of core tissue biopsies, taken from selected regions of paraffin donor blocks, and placed in recipient array paraffin block (5). As a result, we can obtain a slide, containing samples from dozens to hundreds of patients.

TMA is a cost-effective and highly efficient method to analyze archived materials and has been approved and verified for use in the diagnosis of many cancers. The use of TMAs combined with immunohistochemistry (IHC), the gold standard in detecting biomarkers in many cancers, may be a valuable approach for the validation of the predictive and diagnostic usefulness of different cancer biomarkers.

Over the last years, researchers have tested different markers by the TMA method, which could be useful in the analyses of many cancers. Ki-67 protein is commonly used in diagnostic histopathology as a proliferation marker that is observed in all phases of the cell cycle. In laryngeal cancers, its increased expression indicates the biological aggressiveness and histological grade of the malignancy $(6,7)$. Many studies have shown that $\mathrm{Ki}-67$ is a prognostic marker in many human cancers such as: breast, prostate, soft tissue sarcoma, meningiomas, nonHodgkin lymphoma and other (7). Minichromosome maintenance proteins (MCM) are a group of recently 
Table I. Clinicopathological characteristics of patients with laryngeal squamous cell cancer.

\begin{tabular}{lc}
\hline Clinicopathological parameter & $\mathrm{n}=51,(\%)$ \\
\hline Age & \\
$\leq 60$ & $25(49)$ \\
$>60$ & $26(51)$ \\
Gender & \\
Male & $43(84)$ \\
Female & $8(16)$ \\
Tumor size (T) & \\
T1-T2 & $7(14)$ \\
T3-T4 & $44(86)$ \\
Lymph nodes (N) & \\
N0 & $29(57)$ \\
N1 & $7(14)$ \\
N2-3 & $15(29)$ \\
Stage of clinical advancement (S) & \\
I-II & $4(8)$ \\
III-IV & $47(92)$ \\
Grade of malignancy (G) & \\
G1 & $11(21)$ \\
G2 & $27(53)$ \\
G3 & $13(26)$ \\
\hline
\end{tabular}

investigated cancer markers, which form a complex that controls the once per cell cycle DNA replication $(6,8,9)$. The MCM complex consists of six members, MCM2 to MCM7, which are observed only in dividing cells, while they are absent in resting, differentiating and senescent cells $(6,10,11)$. MCM2-7 are members of the pre-replication complex, which binds to replication initiation sites, and due to its helicase activity, allows the process of DNA synthesis $(6,12,13)$. Additionally, recent studies have shown increased expression of MCMs in cancers, speculating on their superiority over the routinely tested Ki-67 (6, 14-16). Many studies have revealed that metallothioneins I/II (MTI/II) are also engaged in the control of cell division and differentiation. It has been shown that MTI/II may stimulate cell proliferation by contributing zinc ions to enzymes involved in DNA replication, as well as by binding toxic metal ions such as cadmium, mercury and lead $(6,17,18)$.

There are few studies that have used the TMA method for the detection of biomarkers in laryngeal squamous cell cancer (LSCC) and there are no data available on the validation of TMAs in these tumors. To our knowledge, we are the first to verify reproducibility and repeatability of proliferation markers characteristic for LSCC progression on TMAs. The aim of our study was to compare TMA results with those of a traditional assessment in whole tissue sections.

\section{Materials and Methods}

Patients. The study was conducted on material from 51 archival paraffin blocks containing LSCC obtained samples from patients
Table II. The scale assessing the levels of MTI/II expression in laryngeal squamous cell cancer (19). Final results consist of $A \times B$ value.

\begin{tabular}{lccc}
\hline $\begin{array}{l}\text { Points } \\
\text { (A) }\end{array}$ & $\begin{array}{c}\text { Percentage of cells } \\
\text { with positive reaction }\end{array}$ & $\begin{array}{c}\text { Points } \\
\text { (B) }\end{array}$ & $\begin{array}{c}\text { Intensity of } \\
\text { the color reaction }\end{array}$ \\
\hline 0 & $0 \%$ & 0 & No \\
1 & $1 \%-10 \%$ & 1 & Poor \\
2 & $11 \%-50 \%$ & 2 & Average \\
3 & $51 \%-80 \%$ & 3 & Strong \\
4 & $>80 \%$ & & \\
\hline
\end{tabular}

operated in 1997-2003 in the J. Babinski Regional Hospital in Wroclaw. The study was approved by Wroclaw Medical University Bioethical Commission (ID No. KB-343/2012). The mean age of patients in the group was 60 years (range $=39-79$ years). Grade of malignancy $(\mathrm{G})$ and clinical stage of disease were based on TNM classification determined according to the guidelines of the International Union Against Cancer (UICC). The available clinicopathological characteristics of patients are shown in Table I.

Tissue samples and TMA construction. Initially, paraffin blocks were cut to conduct hematoxylin and eosin (HE) staining as well as to prepare sections for IHC reactions on whole sections (WS). The HE stained slides were examined by two independent pathologists, under a light microscope (BX42; Olympus, Tokyo, Japan). Subsequently, the HE slides were scanned using the Pannoramic Midi II histological scanner (3DHistech, Budapest, Hungary). Using the Pannoramic Viewer Program (3DHistech), 3 representative cancer sites with a core size of $1.5 \mathrm{~mm}$ were selected, followed by their transfer to the tissue recipient arrays using the TMA Grand Master (3DHistech).

IHC. Immunohistochemical reactions were performed on paraffin sections $(4 \mu \mathrm{m})$ mounted on Superfrost Plus slides (Menzel Gläser, Braunschweig, Germany) for WS as well as TMA sections. Deparaffinization, hydration and thermal demasking of epitopes were performed using Pre-Treatment Link Station (Dako, Glostrup, Denmark). The slides were incubated for $20 \mathrm{~min}$ at $97^{\circ} \mathrm{C}$ with Target Retrieval Solution (low $\mathrm{pH}$ for Ki-67 and high $\mathrm{pH}$ for MCM3, 5, 7 and MT I/II; Agilent Technologies, Santa Clara, CA, USA) in PT Link Rinse Station. The sections were then washed in Tris-buffered saline and incubated with primary antibodies: anti-Ki-67 (MIB-1, 1:100; Dako), anti-MCM3 (101, 1:50; Novocastra Laboratories, Newcastle, UK), anti-MCM5 (E-10, 1:100; Santa Cruz Biotechnology, Dallas, TX, USA) anti-MCM7 (DCS-141.1, 1:50; Leica Biosystem, Buffalo Grove, IL, USA) and anti-MTI/II (E9, 1:100; Dako) in a Link48 Autostainer (Dako; room temperature, $20 \mathrm{~min}$ ). EnVision FLEX (Dako) was used for visualization of the antigens, in accordance with the manufacturer's instructions.

Evaluation of the IHC reaction. Two independent pathologists conducted the evaluation separately. The intensity of Ki-67, MCM3, MCM5 and MCM7 expression was determined with the use of a five-point scale ( 0 - no expression, 1 point - 1-10\%, 2 points - 11 $25 \%, 3$ points $-26-50 \%, 4$ points $>50 \%$ ) (6). For the estimation of $\mathrm{MTI} / \mathrm{II}$ cytoplasmic levels, the semiquantitative Immunoreactive Score (IRS) method was used according to Remmele and Stegner 

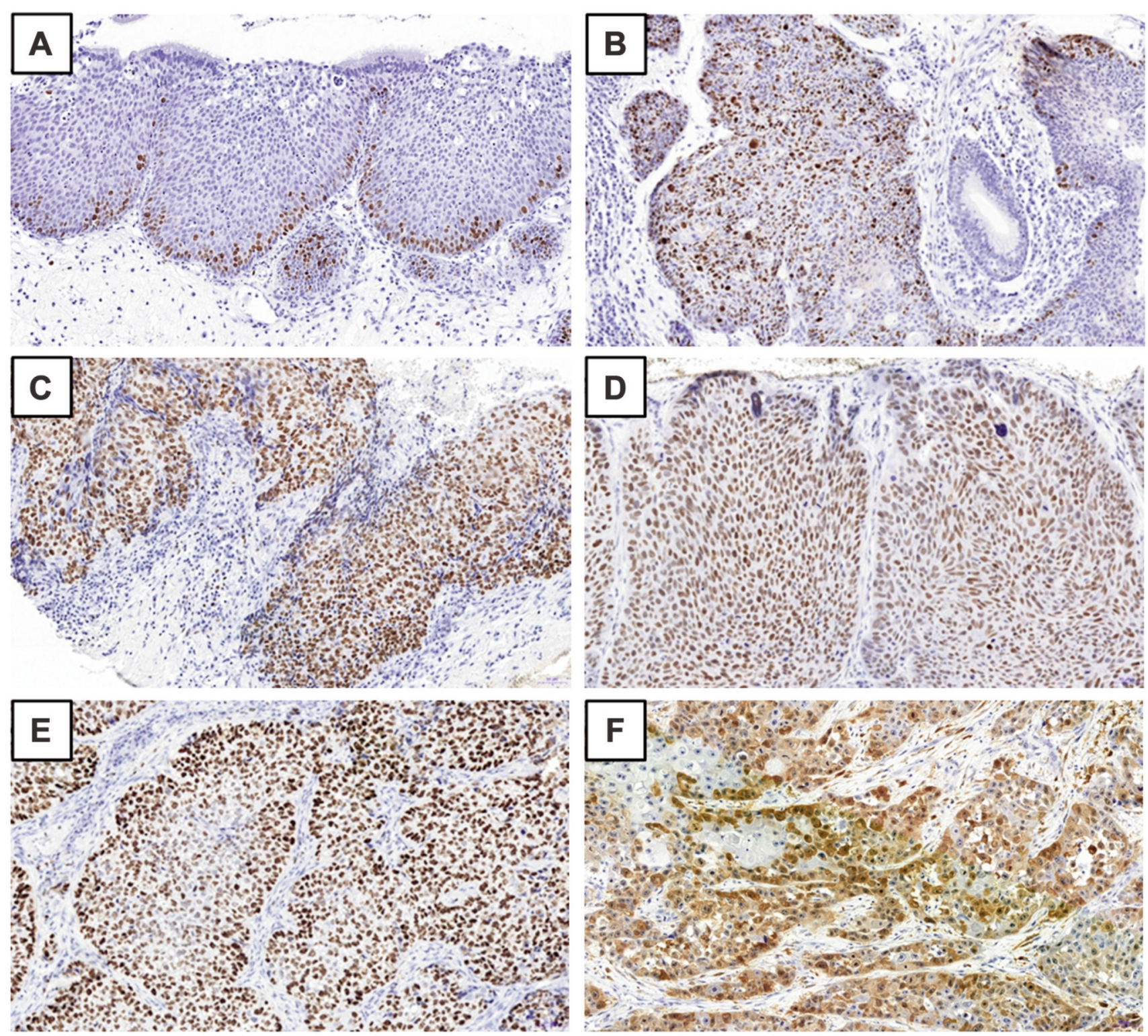

Figure 1. The expression of the tested markers on TMA sections: A) Ki-67 antigen in control tissue (papilloma) and B) in laryngeal squamous cell cancer (LSCC); minichromosome maintenance proteins in LSCC: C) MCM3, D) MCM5, E) MCM7 and F) metallothionein I/II (MTI/II).

(19) (Table II). For the evaluation of Ki-67, MCM3,5,7 and MTI/II expression on WS as well as on TMA, three fields with the highest marker expression were chosen (hot spot) and the estimation was performed under $\times 400$ magnification using the BX42 light microscope (Olympus). The final result for each sample was an average of three hot spot percentages.

Statistical analysis. All statistical analyses were performed using GraphPad Prism 5 (GraphPad, San Diego, CA, USA). Kolmogorov-Smirnov test was used to check the normality of the distribution. The Spearman rank correlation test was used to evaluate the associations between the tested markers. By Mann Whitney $U$-test differences in expressions were examined, whereas
Bland-Altman test was used to reveal the level of bias between the two tested techniques, i.e. WS vs. TMA. p-Values $<0.05$ indicated statistical significance.

\section{Results}

In all analyzed LSCC samples (WS and TMA) clear nuclear IHC expression was disclosed for Ki-67 antigen (Figure 1A, $\mathrm{B}$ ), as well for MCM3, 5, 7 (Figure 1C, D, E), and cytoplasmic expression for MTI/II (Figure 1F).

The Spearman rank correlation test revealed moderate positive correlation in regard to Ki-67 expression: WS vs. 
A

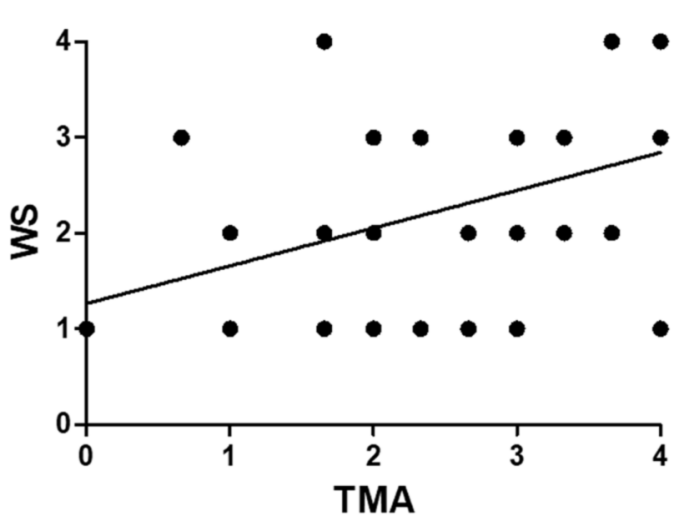

B

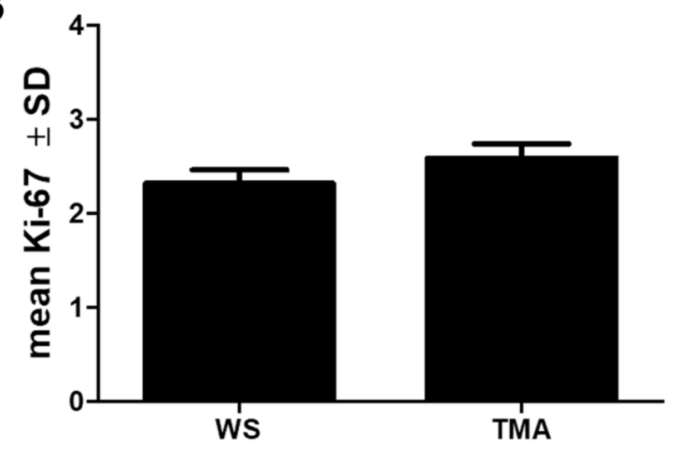

C

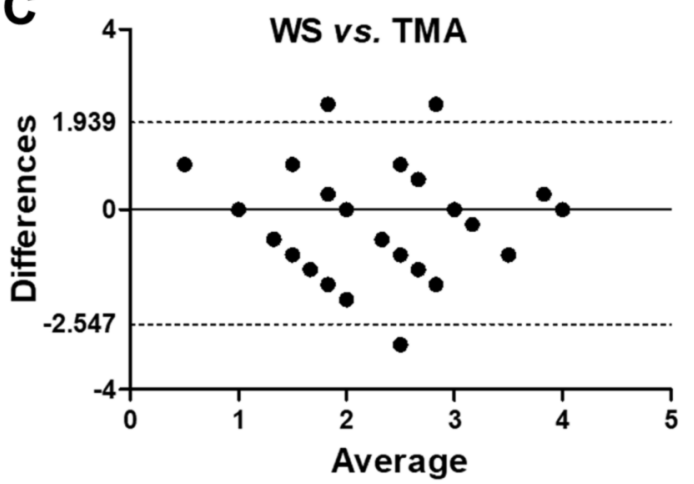

Figure 2. The expression of Ki-67 antigen in whole section (WS) and tissue microarray (TMA): A) Spearman rank correlation test, B) MannWhitney U-test and C) Bland-Altman test. SD: Standard deviation.

TMA ( $\mathrm{r}=0.38, p=0.007$; Figure 2A), and strong positive correlation in regard to the rest of tested markers: MCM3, WS $v s$. TMA ( $\mathrm{r}=0.49, p=0.0004$; Figure 3A); MCM5, WS $v s$. TMA ( $\mathrm{r}=0.61, p<0.0001$; Figure 4A); MCM7, WS $v s$. TMA $(\mathrm{r}=0.59, p<0.0001$; Figure $5 \mathrm{~A})$; and MTI/II WS vs. TMA $(\mathrm{r}=0.66, p<0.0001$; Figure 6A).

The Mann Whitney $U$-test showed significant differences between the mean expression of MCM3 ( $p<0.01$; Figure 3B), MCM7 ( $p<0.0001$; Figure 5B) and MTI/II $(p<0.0001$; Figure

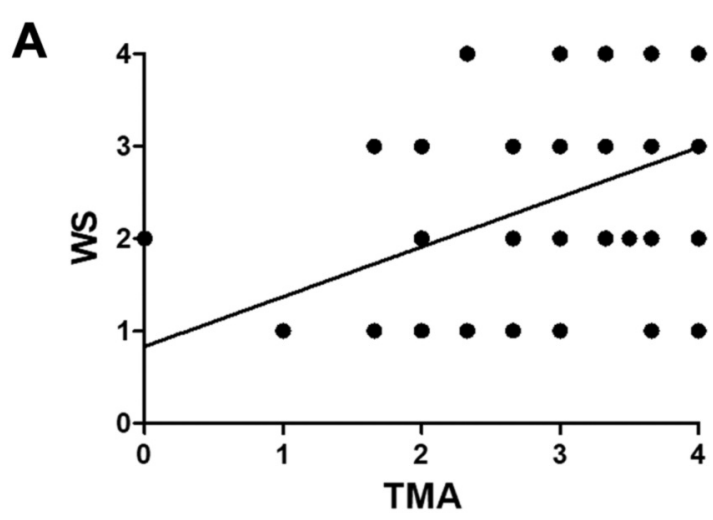

B
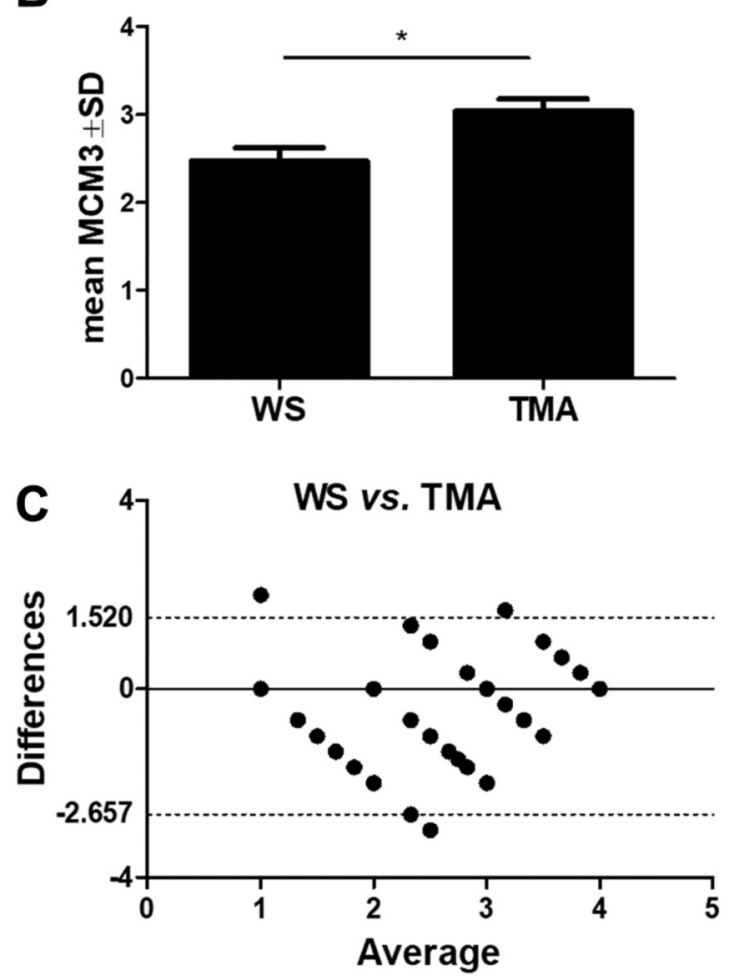

Figure 3. The expression of MCM3 antigen in whole section (WS) and tissue microarray (TMA): A) Spearman rank correlation test, B) MannWhitney U-test and C) Bland-Altman test. SD: Standard deviation; $* p<0.01$.

6B) in WS vs. TMA. In the case of Ki-67 and MCM5, differences were insignificant (Figures 2B and 4B, respectively). Moreover, only in regard to MTI/II analysis, the mean expression on WS was stronger than that on TMA (Figure 6B).

The Bland-Altman test revealed a low level of bias $(<10 \%)$ in regard to Ki-67, TMA $v s$. WS (bias -0.30 , SD of bias 1.14; Figure 2C), and MCM5, TMA vs. WS (bias -0.02, SD of bias 0.97; Figure 4C). Moderate level of bias (10- 
A

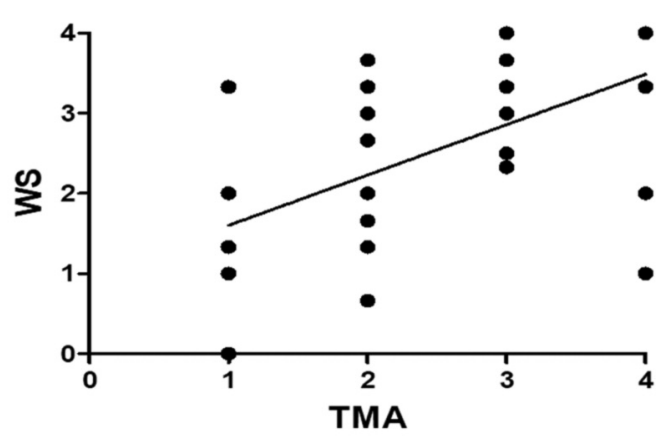

B
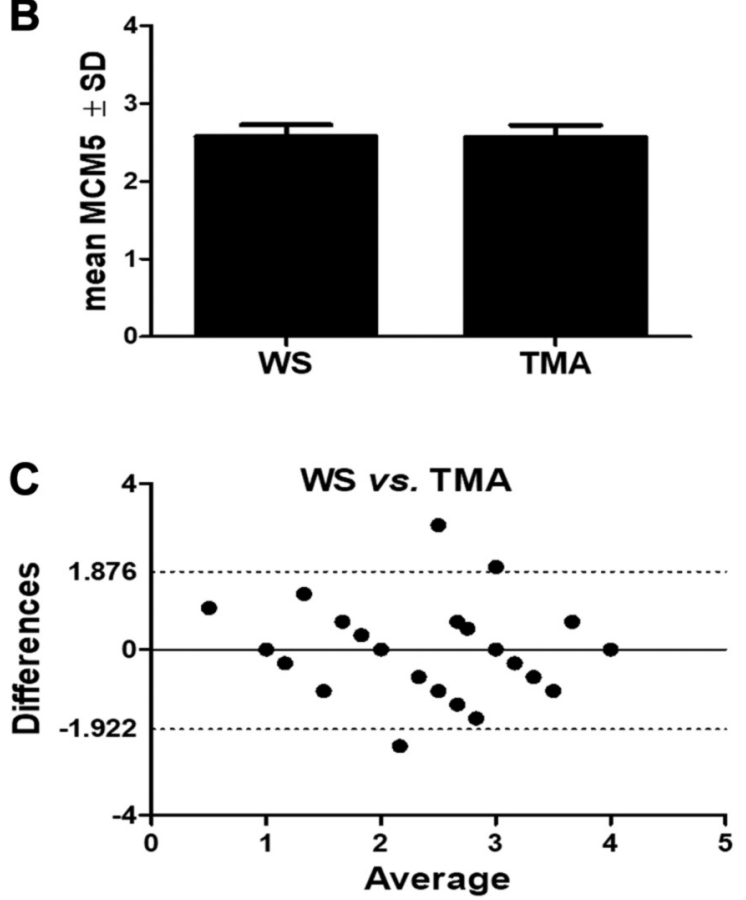

Figure 4. The expression of MCM5 antigen in whole section (WS) and tissue microarray (TMA): A) Spearman rank correlation test, B) MannWhitney U-test and C) Bland-Altman test. SD: Standard deviation.

$20 \%$ ) was revealed in regard to MCM3, TMA vs. WS (bias -0.57 , SD of bias 1.07; Figure 3C), whereas high level of bias $(>20 \%)$ was found for MCM7, TMA vs. WS (bias 1.14, SD of bias 0.87 ; Figure 5C), and MTI/II, TMA vs. WS (bias 2.48, SD of bias 2.79; Figure 6C).

\section{Discussion}

In recent years, the TMA technique has been commonly used to evaluate various biomarkers for their diagnostic potential abilities (of molecular alteration) in different cancers (20-23). TMAs allow the analysis of many tissue
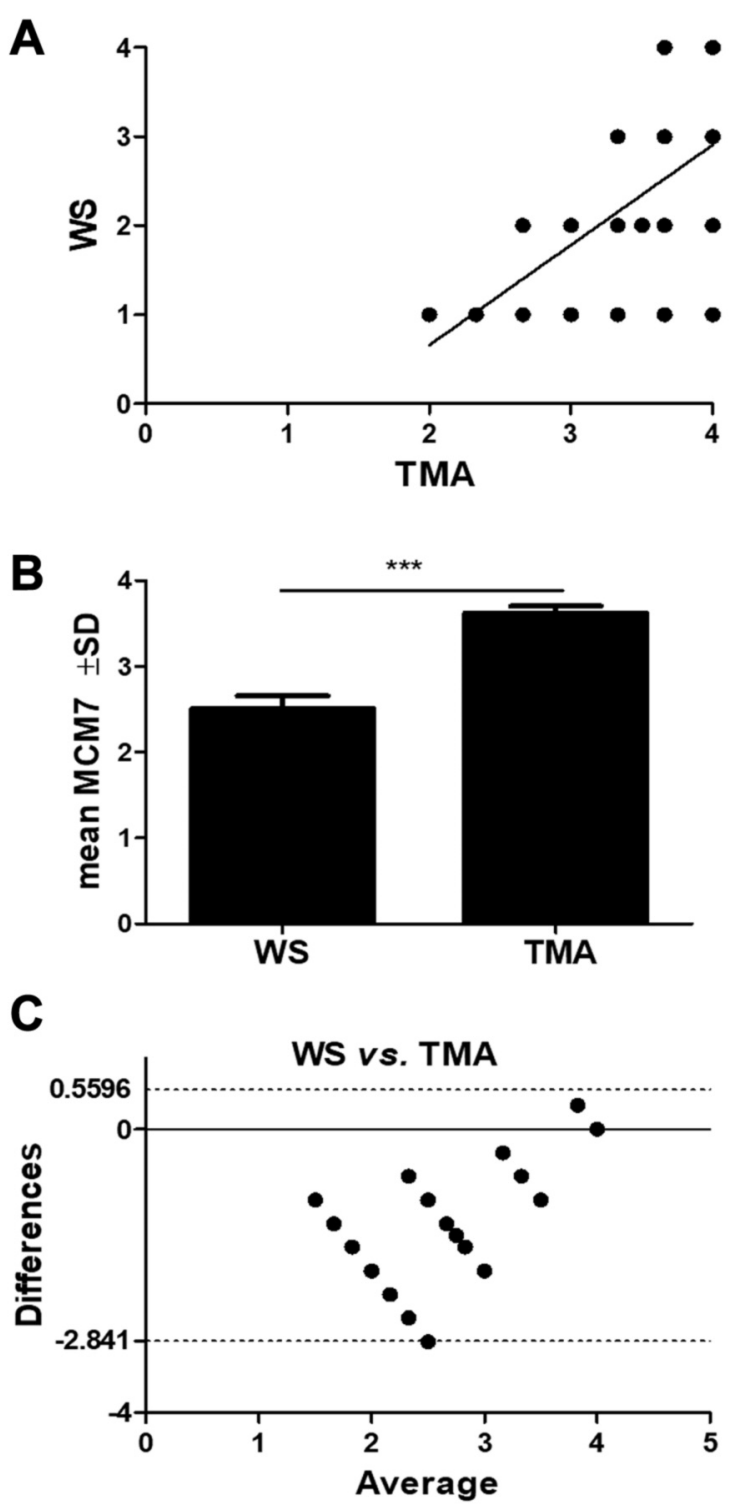

Figure 5. The expression of MCM7 antigen in whole section (WS) and tissue microarray (TMA): A) Spearman rank correlation test, B) MannWhitney U-test and C) Bland-Altman test. SD: Standard deviation; $* * * p<0.0001$.

specimens using uniform experimental conditions; therefore, its use has been validated in many cancers by comparing the expression of specific proteins on whole tissue sections with TMA $(5,20-22)$. Researchers are still trying to optimize and improve the TMA technique and claim that it has many advantages and disadvantages. In this study, we examined the expression of Ki-67, MCM3, 5, 7 and MTI/II and analyzed the correlation among these markers in whole tissue sections and TMAs. The Spearman's correlation showed moderate correlation in the 
A

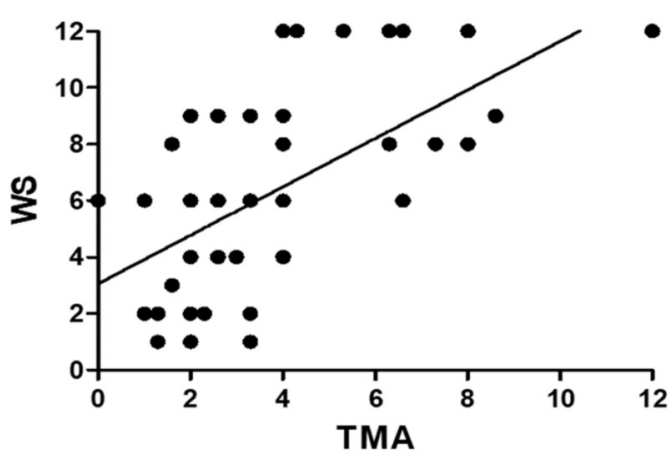

B

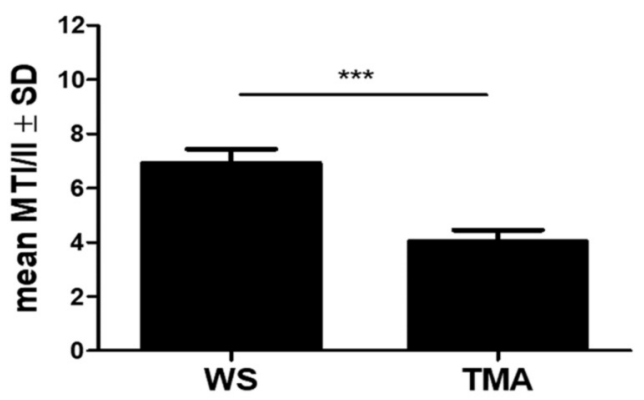

C

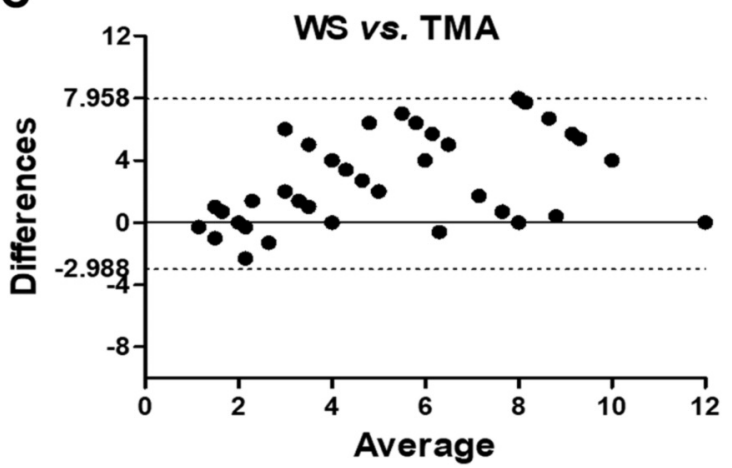

Figure 6. The expression of MTI/II in whole section (WS) and tissue microarray (TMA): A) Spearman rank correlation test, B) MannWhitney U-test and C) Bland-Altman test. SD: Standard deviation; $* * * p<0.0001$.

case of Ki-67 in WS vs. TMA and strong positive correlation in regard to MCM3, 5, 7 and MTI/II in WS as well as in TMAs. The Man-Whitney test revealed that the nuclear expression of the tested antigens was stronger on TMAs material with regard to nuclear expression, while cytoplasmic expression of MTI/II was stronger in WS material. We also used the Bland-Altman method in order to compare the obtained results. We noticed low level of bias in the cases of Ki-67, as well MCM5, TMA vs. WS, moderate in regard to MCM3 and high level of bias for MCM7 and MTI/II, which may indicate some limitations and imperfections of the compared methods.
One of the most known limitations of TMA is the small size of the core used for construction of TMA, which may not precisely represent the features of the whole tissue section especially because of the heterogeneity of the cancer lesions and the different expression patterns. For these reasons, may not be a proper technique for some biomarkers $(1,2,20,24,25)$. Some studies have indicated incompatibility between whole section and TMA, which may be due to the heterogeneity in neoplastic lesions $(21,25)$. However, many studies have shown good concordance rate between TMA and WS.

Chavan et al. have compared expression of ER, PR and Her2/neu markers in WS and TMA and observed good concordance between the tested methods. The rates for ER, PR, Her2/neu were $76.2 \%, 82.1 \%$ and $100 \%$, respectively, all statistically significant (25). Similarly, Gulbahce et al. have confirmed the capability of determining the expression of ER in WS and TMA, with only $5.5 \%$ discrepancy. They claimed that the discrepancy between WS and TMA could be reduced if more cores from individual cases were available (21). Also, in our previous study, we showed no significant differences between the expression of Ki-67 and MCM2 in WS and TMA in ductal breast cancer (11), which are in concordance with this study.

Thus, the usefulness of TMAs has been verified in many cancer types by comparison of the expression of certain biomarkers in TMA core biopsies specimens with their expression in whole tissue sections of the donor blocks by IHC (5). The current TMAs were constructed using cores, ranging from 0.6-2.0 in diameter, of tissue punched from donor blocks $(1,5,26)$. In our study, we used a core size of $1.5 \mathrm{~mm}$, which is claimed to be better than smaller size cores (1). However, some authors claim that a bigger size can accelerate depletion of the donor block (26), which we also observed in some cases.

\section{Conclusion}

In summary, in this study we obtained a good concordance between the expression of the tested markers on WS and TMA. We estimated and validated for the first time the TMA method in LSCC. We compared IHC results for Ki67, MCM3, 5, 7 proliferation markers and MTI/II on WS and TMA. Taking into account the Mann-Whitney and Bland-Altman tests, the repeatability of our results was satisfactory for Ki-67 and MCM5. Therefore, it is reasonable to reevaluate the obtained results on a larger group of cases, and other punch diameters. Since, we observed insignificant differences between Ki-67 and MCM5 with regard to the tested methods, we suggest that TMA may be an effective and reliable method for evaluating these biomarkers in LSCC. 


\section{Conflicts of Interest}

The Authors declare that there are no conflicts of interest regarding this study.

\section{Authors' Contributions}

UC and PD conceived and designed the experiments. WP collected material from patients. AP performed the IHC reactions. UC analyzed the data. UC and $\mathrm{KN}$ wrote the manuscript. CK and MPO reviewed and revised the manuscript. All Authors have read and approved the final version of the manuscript.

\section{References}

1 Eckel-Passow JE, Lohse CM, Sheinin Y, Crispen PL, Krco CJ and Kwon ED: Tissue microarrays: one size does not fit all. Diagn Pathol 5: 48, 2010. PMID: 20609235. DOI: 2010.10.1186/ 1746-1596-5-48

2 Zlobec I, Suter G, Perren A and Lugli A: A next-generation tissue microarray (ngTMA) protocol for biomarker studies. J Vis Exp (91): 51893, 2014. PMID: 25285857. DOI: 10.3791/51893

3 Battifora H: Methods in laboratory investigation. The multitumor (sausage) tissue block: Novel method for immunohistochemical antibody testing. Lab Investig 55: 244-248, 1986. PMID: 3525985 .

4 Kononen J, Bubendorf L, Kallioniemi A, Bärlund M, Schraml P, Leighton S, Torhorst J, Mihatsch MJ, Sauter G and Kallioniemi OP: Tissue microarrays for high-throughput molecular profiling of tumor specimens. Nat Med 4: 844-847, 1998. PMID: 9662379. DOI: $10.1038 / \mathrm{nm} 0798-844$

5 Soares Gonçalves Cunha K, Cunha Caruso A, Soares Gonçalves A, Gonçalves Bernardo V, Rodrigues Cordovil Pires A, Carvalho Da Fonseca E, Antônio Silvestre De Faria P, Esmeraldo Da Silva L, Geller M, Soares De Moura-Neto R and Silami Lopes V: Validation of tissue microarray technology in malignant peripheral nerve sheath tumours. J Clin Pathol 62: 629-633, 2009. PMID: 19318344. DOI: 10.1136/jcp.2008.063081

6 Nowinska K, Chmielewska M, Piotrowska A, Pula B, Pastuszewski W, Krecicki T, Podhorska-Okołow M, Zabel M and Dziegiel P: Correlation between levels of expression of minichromosome maintenance proteins, Ki-67 proliferation antigen and metallothionein I/II in laryngeal squamous cell cancer. Int J Oncol 48: 635-645, 2016. PMID: 26648405. DOI: 10.3892/ijo.2015.3273

7 Endl E, Kausch I, Baack M, Knippers R, Gerdes J and Scholzen T: The expression of Ki-67, MCM3, and p27 defines distinct subsets of proliferating, resting, and differentiated cells. J Pathol 195: 457-462, 2001. PMID: 11745678. DOI: 10.1002/path.978

8 Whitfield ML, George LK, Grant GD and Perou CM: Common markers of proliferation. Nat Rev Cancer 6: 99-106, 2006. PMID: 16491069. DOI: 10.1038/nrc1802

9 Nowińska K and Dzięgiel P: The role of MCM proteins in cell proliferation and tumorigenesis. Postepy Hig Med Dosw 64: 627-635, 2010. PMID: 21160097.

10 Leone G, DeGregori J, Yan Z, Jakoi L, Ishida S, Williams RS and Nevins JR: E2F3 activity is regulated during the cell cycle and is required for the induction of S phase. Genes Dev 12: 2120-2130, 1998. PMID: 9679057.
11 Nowinska K, Ciesielska U, Piotrowska A, Jablonska K, Partynska A, Paprocka M, Zatonski T, Podhorska-Okolow M and Dziegiel $\mathrm{P}$ : MCM5 expression is associated with the grade of malignancy and Ki-67 antigen in LSCC. Anticancer Res 39: 2325-2335, 2019. PMID: 31092424. DOI: 10.21873/anticanres.13349

12 Kobierzycki C, Pula B, Wojnar A, Podhorska-Okolow M and Dziegiel P: Tissue microarray technique in evaluation of proliferative activity in invasive ductal breast cancer. Anticancer Res 32: 773-777, 2012. PMID: 22399591.

13 Moyer SE, Lewis PW and Botchan MR: Isolation of the Cdc45/Mcm2-7/GINS (CMG) complex, a candidate for the eukaryotic DNA replication fork helicase. Proc Natl Acad Sci USA 103: 10236-10241, 2006. PMID: 16798881. DOI: 10.1073/ pnas.0602400103

14 Giaginis C, Georgiadou M, Dimakopoulou K, Tsourouflis G, Gatzidou E, Kouraklis G and Theocharis S: Clinical significance of MCM-2 and MCM-5 expression in colon cancer: association with clinicopathological parameters and tumor proliferative capacity. Dig Dis Sci 54: 282-291, 2009. DOI: 10.1007/s10620008-0305-z

15 Yu S, Wang Y, Chang JY and Shen W: Increased expression of MCM5 is significantly associated with aggressive progression and poor prognosis of oral squamous cell carcinoma. J Oral Pathol Med 43: 344-349, 2014. PMID: 24245508. DOI: 10.1111/jop.12134

16 Eissa S, Matboli M and Shehata HH: MicroRNA-10b and minichromosome maintenance complex component 5 gene as prognostic biomarkers in breast cancer. Tumor Biol 36(6): 4487-4494, 2015. PMID: 25596707. DOI: 10.1007/s13277-0153090-2

17 Kobierzycki C, Pula B, Skiba M, Jablonska K, Latkowski K, Zabel M, Nowak-Markwitz E, Spaczynski M, Kedzia W, Podhorska-Okolow $\mathrm{M}$ and Dziegiel P: Comparison of minichromosome maintenance proteins (MCM-3, MCM-7) and metallothioneins (MT-I/II, MT-III) expression in relation to clinicopathological data in ovarian cancer. Anticancer Res 33: 5375-5384, 2013. PMID: 24324072.

18 Domoslawski P, Pula B, Olbromski M, Wojtczak B, Lukienczuk $\mathrm{T}$, Podhorska-Okolow $\mathrm{M}$ and Dziegiel $\mathrm{P}$ : Expression of metallothionein I/II and Ki-67 antigen in Graves' disease. Anticancer Res 38: 6847-6853, 2018. PMID: 30504400. DOI: 10.21873/anticanres.13059

19 Remmele W and Stegner HE: [Recommendation for uniform definition of an immunoreactive score (IRS) for immunohistochemical estrogen receptor detection (ER-ICA) in breast cancer tissue]. Pathologe 8: 138-140, 1987. PMID: 3303008.

20 Dias EP, Picciani BLS, Santos VDCBD and Cunha KS: A simple technique to construct tissue macroarrays. J Clin Pathol 71: 890894, 2018. PMID: 29798839. DOI: 10.1136/jclinpath-2018205076

21 Gulbahce HE, Gamez R, Dvorak L, Forster C and Varghese L: Concordance between tissue microarray and whole-section estrogen receptor expression and intratumoral heterogeneity. Appl Immunohistochem Mol Morphol AIMM 20: 340-343, 2012. PMID: 22495371. DOI: 10.1097/PAI.0b013e318241ca14

22 Cappellesso R, Fassan M, Hanspeter E, Bornschein J, S.G. d'Amore E, Cuorvo L V., Mazzoleni G, Barbareschi M, Pizzi M, Guzzardo V, Malfertheiner P, Micev M, Guido M, Giacomelli L, Tsukanov VV, Zagonel V, Nitti D and Rugge M: HER2 status in gastroesophageal cancer: a tissue microarray study of 1040 
cases. Hum Pathol 46: 665-672, 2015. PMID: 25800719. DOI: 10.1016/j.humpath.2015.02.007

23 Fitzgibbons PL, Dillon DA, Alsabeh R, Berman MA, Hayes DF, Hicks DG, Hughes KS and Nofech-Mozes S: Template for reporting results of biomarker testing of specimens from patients with carcinoma of the breast. Arch Pathol Lab Med 138: 595601, 2014. PMID: 24236805. DOI: 10.5858/arpa.2013-0566-CP

24 Mulrane L, Gallagher WM and O'Connor DP: Assessment of significance of novel proteins in breast cancer using tissue microarray technology. Humana Press, New York, NY, pp. 311325, 2017.

25 Chavan SS, Ravindra S and Prasad M: Breast biomarkerscomparison on whole section and tissue microarray section. J Clin Diagn Res 11: EC40-EC44, 2017. PMID: 28511394. DOI: 10.7860/JCDR/2017/25088.9573
26 Eskaros AR, Egloff SAA, Boyd KL, Richardson JE, Hyndman $\mathrm{ME}$ and Zijlstra A: Larger core size has superior technical and analytical accuracy in bladder tissue microarray. Lab Investig 97: 335-342, 2017. PMID: 28112755. DOI: 10.1038/labinvest. 2016.151

Received July 17, 2020

Revised August 3, 2020

Accepted August 5, 2020 